\title{
Características de Vibrio parabaemolyticus isolados de mexilhões (Perna perna) comercializados em Niterói, Rio de Janeiro
}

\author{
Characteristics of Vibrio parabaemolyticus isolated from mussels \\ (Perna perna) commercialized at Niterói, Rio de Janeiro
}

\author{
Christiane Soares Pereira1, Cristina de Albuquerque Possas ${ }^{2}$, \\ Célio Mauro Viana ${ }^{3}$ e Dália dos Prazeres Rodrigues ${ }^{1}$
}

\begin{abstract}
RESUMO
O ecossistema marinho é o habitat natural de bactérias como Vibrio parahaemolyticus, um importante patógeno causador de gastrenterite bumana associada a consumo de alimentos marinhos. Na presente investigação, foi avaliada a presença de V. parahaemolyticus a partir de 86 amostras de mexilhões in natura e pré-cozidos. Vibrio parahaemolyticus foi isolado a partir de 11,6\% dos mexilhões in natura e pré-cozidos avaliados. Todas as cepas avaliadas demonstraram-se urease positivas e 28,5\% Kanagawa positivas sugerindo um potencial patogênico para o homem. Houve a predominância do sorotipo 010:K52 e a identificação da cepa emergente 03:K6. Esses resultados apontam para a relevância epidemiológica de $\mathrm{V}$. parahaemolyticus em casos de gastrenterite humana após consumo de mexilhões sem cozimento adequado $\left(100^{\circ} \mathrm{C} / 15 \mathrm{~min}\right)$. Além disso, é importante alertar as autoridades de Vigilância Sanitária no Brasil quanto a sua presença na cadeia alimentar e seus riscos para a Saúde Pública.
\end{abstract}

Palavras-chaves: Vibrio parahaemolyticus. Kanagawa. Sorotipos. Mexilhões.

\begin{abstract}
The marine ecosystem is the natural habitat of bacteria like Vibrio parahaemolyticus, an important pathogen that cause buman gastroenteritis associated with seafood consumption. In the present investigation, the presence of $\mathrm{V}$. parahaemolyticus in 86 in natura and precooked mussel samples was evaluated. Vibrio parahaemolyticus was isolated from $11.6 \%$ of the in natura and precooked mussels. All strains tested were urease-positive and 28.5\% were Kanagawa-positive, which suggests that they have pathogenic potential for humans. There was predominance of the 010:K52 serotype and the emerging 03:K6 strain was identified. These results show the epidemiological relevance of $\mathrm{V}$. parahaemolyticus in cases of human gastroenteritis following mussel consumption without adequately cooking them $\left(100^{\circ} \mathrm{C} / 15 \mathrm{~min}\right)$. Moreover, it is important to alert the Brazilian Sanitary Surveillance authorities regarding their presence in the food chain and their public health risks.
\end{abstract}

Key-words: Vibrio parahaemolyticus. Kanagawa. Serotypes. Mussels.

0 cultivo comercial de mexilhões é uma prática que tem crescido em todas as regiões litorâneas do Brasil, devido às riquezas dos recursos naturais do ecossistema aquático. Os mexilhões são animais micrófagos que se alimentam de partículas e microrganismos em suspensão na água. 0 processo de filtração desses moluscos bivalves permite a retenção e acúmulo de poluentes e bactérias patogênicas ao homem ${ }^{18}$.
Vibrio parahaemolyticus é uma das principais espécies do gênero Vibrio tendo sido reconhecido como um patógeno relevante distribuído nas regiões costeiras de clima temperado e tropical em todo o mundo ${ }^{11}$. A capacidade do microrganismo em causar manifestações gastrentéricas sob a forma de surtos ou casos esporádicos associados à ingestão de pescado e moluscos bivalves sem cocção ou insuficientemente cozidos aumenta

\footnotetext{
1. Laboratório de Enterobactérias, Departamento de Bacteriologia, Instituto Oswaldo Cruz, Fundação Oswaldo Cruz, Rio de Janeiro, RJ. 2. Escola Nacional de Saúde Pública Sérgio Arouca, Fundação Oswaldo Cruz, Rio de Janeiro, RJ. 3. Laboratório de Microbiologia de Alimentos, Faculdade de Veterinária, Universidade Federal Fluminense, Rio de Janeiro, RJ.

Endereço para correspondência: Drª Christiane Soares Pereira. Laboratório de Enterobactérias/Dept ${ }^{\circ}$ Bacteriologia/IOC/FIOCRUZ. Av. Brasil 4365, sala 320, Manguinhos, 21045-900 Rio de Janeiro, RJ.

e-mail: chrisspm@ioc.fiocruz.br

Recebido para publicação em 29/12/2005

Aceito em 17/1/2007
} 
sua relevância para a Vigilância Sanitária de Alimentos e Saúde Pública $^{112}$.

Em nosso meio, diversos estudos revelaram a incidência de V. parahaemolyticus no ambiente aquático, particularmente salino e também a partir de alimentos de origem marinha. Nestes, é confirmada a assertiva quanto à frequiência de isolamento desse microrganismo, mais elevada nos meses de verão, tanto nas zonas temperadas como nas tropicais, sugerindo uma característica de sazonalidade $^{10}$.

A presença de duas hemolisinas termoestáveis denominadas thermostable direct bemolysin (TDH) e thermostable related hemolysin (TRH), além de uma hemolisina termolábil denominada thermolabile hemolysin(TLH) são consideradas como os principais fatores de virulência. Sua caracterização permite discriminar TDH entre cepas patogênicas e não-patogênicas, através da reação de beta hemólise nos eritrócitos humanos em teste fenotípico designado teste de Kanagawa. Por outro lado, a capacidade de hidrolisar uréia, apresentada por algumas cepas tem sugerido uma forte associação com a presença de TRH. A presença desses fatores de virulência geralmente ocorre em cepas oriundas de achados clínicos, enquanto naquelas isoladas de ambiente ou alimentos marinhos são apontados resultados negativos ou com percentuais oscilantes de até $1 \%$ no teste de Kanagawa e hidrólise de uréia ${ }^{45} 15$.

Tendo em vista, o reconhecimento da relevância epidemiológica de tais microrganismos, autóctones no ambiente marinho, a viabilidade destes no pescado, o hábito alimentar de consumo de mexilhões insuficientemente cozidos, representa risco para a população consumidora. Deste modo, objetivou-se na presente investigação avaliar sua presença em mexilhões in natura e pré-cozidos coletados de uma Estação Experimental de Cultivo no Rio de Janeiro, caracterizar os sorovares circulantes de V. parahaemolyticus e verificar seu potencial patogênico da bactéria através do teste de Kanagawa e produção de urease.

\section{MATERIAL E MÉTODOS}

Foram realizadas coletas quinzenais de mexilhões (Perna perna) e analisadas um total de 86 amostras, sendo 43 in natura (animal íntegro no interior valvar) e 43 pré-cozidas (submetido ao processo de aquecimento em vapor d'água por aproximadamente 3 minutos para retirada das valvas e subseqüente comercialização da parte comestível), no período de janeiro a dezembro do ano 2000. Os mexilhões foram coletados por pescadores da Estação Experimental de Cultivo situada em Jurujuba no município de Niterói (RJ). As amostras, segundo informações dos profissionais, foram coletadas em 19 pontos de coleta distintos localizados na Baía de Guanabara.

As amostras de mexilhões (in natura e pré-cozidos) foram devidamente acondicionadas em embalagem de polietileno a qual é utilizada para comercialização, identificadas e colocadas em recipiente de isolamento térmico, transportadas à temperatura de 6-10 ${ }^{\circ}$. Estas foram, em sequiência, processadas no Laboratório de Enterobactérias, Depto. Bacteriologia, Instituto Oswaldo Cruz,
FIOCRUZ, onde as análises microbiológicas foram realizadas, dentro de um prazo que não ultrapassou duas horas.

0 procedimento utilizado nos dois grupos de amostras esteve representado inicialmente pela pesagem de $25 \mathrm{~g}$ de mexilhões in natura (parte carnea e líquido intervalvar) e tomada como amostra $25 \mathrm{~g}$ de mexilhões pré-cozidos. 0 procedimento a seguir foi comum para os dois grupos de amostras, nos quais foi efetuada uma diluição (10:1) em solução salina de Butterfield (225mL) e homogeneização em Warning-Blender $(8,000 \mathrm{rpm})$ por um minuto. Desta, duas alíquotas de $1 \mathrm{~mL}$ do homogeinato foram semeadas em Água Peptonada Alcalina (APA) acrescida de 1\% de cloreto de sódio ( $\mathrm{NaCl}$ ) e APA com $3 \%$ de $\mathrm{NaCl}$ incubados a $37^{\circ} \mathrm{C}$ por 18- 24 horas $^{3}$.

Após esse período, procedeu-se o isolamento em Ágar TCBS (Tiossulfato Citrato Bile Sacarose), incubado a $37^{\circ} \mathrm{C}$ por um período de 18 a 24 horas. As colônias suspeitas ( 5 a 10) foram repicadas para meios de triagem (Kligler Iron Agar e Lysine Iron Agar) e Agar nutriente acrescido de $1 \%$ de $\mathrm{NaCl}$. Após a seleção das cepas citocromo-oxidase positivas, foram realizados testes bioquímicos, baseados na resistência ao agente vibriostático 0/129 (2,4 diamino-6,7 diisopropil-pteridina), produção de ONPG ( $\alpha$ nitrofenil, $\beta$-D galactosidase) produção de acetoína em meio Voges Proskauer, fermentação da glicose, sacarose, arabinose e manose e utilização de aminoácidos (lisina e ornitina descarboxilase e arginina dehidrolase) a fim de obter a identificação conclusiva das cepas isoladas ${ }^{3}$.

A caracterização antigênica, para identificação do sorotipo, foi realizada em placa de vidro para observação da aglutinação das cepas frente aos soros poli e monovalentes (Denka Seiken Co. Ltda, Tókio, Japão). Em sequiência foram avaliadas a produção de urease em meio Agar Uréia de Christensen (Oxoid) e hemólise total em Agar Wagatsuma, designado teste de Kanagawa visando conhecer seu potencial de patogenicidade 3 .

\section{RESULTADOS E DISCUSSÃO}

Do total geral de 86 amostras de mexilhões (Perna perna) analisados, a presença de Vibrio parahaemolyticus foi detectada em $10(11,6 \%)$ amostras in natura e pré-cozidas isoladas a partir do APA $1 \%(\mathrm{NaCl})$, perfazendo o total de 17 cepas das quais $11(64,7 \%)$ a partir das amostras in natura e $6(35,3 \%)$ cepas a partir dos espécimes pré-cozidos. Comparativamente, o APA 1\% $(\mathrm{NaCl})$ apresentou resultados mais significativos no isolamento de $V$. parahaemolyticus, uma vez que não foi isolada nenhuma cepa do microrganismo a partir do APA 3\% ( $\mathrm{NaCl})$.

A caracterização antigênica das cepas avaliadas permitiu a classificação em 10 sorotipos diferentes assim distribuídos: 010:K52 (3) 09:K56 (2), 010:KUN (2), 01:K25 (1) , 02:K3 (1), 02:K30 (1) , 03:K6 (1), 05:KUN (1), 08:K15 (1), e 08:K60 (1). Entre estes sorotipos destaca-se 03:K6, isolado primariamente em surto na Índia em 1996 e desde então reconhecido como uma cepa emergente capaz de produzir surtos pandêmicos em diversas regiões do mundo. 0 sorotipo 01:K25 também apresenta relevância, pois tem sido reconhecido por causar surtos de 
gastrenterite associado ao consumo de alimentos marinhos e considerado um sorotipo fortemente associado ao clone $03: \mathrm{K} 6^{4514}$.

Os sorotipos mais comumente identificados no Brasil nas duas últimas décadas foram 02:K28, 03:K5, 010:K52, 05:K17 e 04:K12 ${ }^{10}$. O primeiro relato de identificação do sorotipo 03:K6 em nosso meio ocorreu em $1997^{16}$, isolada de pescado, contudo, desde este período não há nenhum registro desse sorotipo envolvido em surto humano no Brasil.

A habilidade de hidrolisar uréia é mencionada como indicador da presença do gene $t r h$, um importante fator de virulência de cepas $V$. parahaemolyticus patogênicas. No presente estudo, todas as cepas avaliadas apresentaram positividade meio agar uréia de Christensen. Embora essa característica seja considerada como um indicativo de patogenicidade, há controvérsias a esse respeito, estudos moleculares revelaram que o gene da urease não influencia diretamente na expressão gênica de TRH ${ }^{15}$.

Em função da sua relevância epidemiológica, 14 cepas de $V$. parahaemolyticus isoladas foram analisadas quanto ao potencial patogênico através do fenômeno de Kanagawa (KP). Os resultados apontaram $4(28,5 \%)$ cepas KP positivas sendo que destas, 3 originaram-se dos mexilhões in natura e apenas uma dos mexilhões pré-cozidos (Tabela 1). Entretanto, as cepas KP negativas apontaram 10 (71,5\%) cepas KP negativas. Embora seja reconhecido que o uso desta metodologia possa resultar em falhas quanto à presença de falsos negativos, sendo apontada como critérios mais susceptíveis, diferentes métodos moleculares, os resultados obtidos mostram-se altamente relevantes tendo em vista os reduzidos percentuais relatados particularmente em países do hemisfério norte, reforçados por estudos recentes que demonstraram que amostras Kanagawa negativas podem não estar completamente isentas de patogenicidade ${ }^{68}$.

Tabela 1- Freqüência e distribuição dos sorotipos de Vibrio parahaemolyticus isoladas de mexilbões in natura e pré-cozidos de acordo com teste de Kanagawa.

\begin{tabular}{|c|c|c|c|c|c|}
\hline \multirow{2}{*}{$\begin{array}{l}\text { Teste de } \\
\text { Kanagawa }\end{array}$} & \multirow{2}{*}{$\begin{array}{c}\text { Amostra } \\
\mathrm{n}^{\underline{0}}\end{array}$} & \multicolumn{4}{|c|}{ APA $1 \%(\mathrm{NaCl})$} \\
\hline & & in natura & sorotipo & pré-cozidos & sorotipo \\
\hline & 7 & 1 & $09: K 56$ & - & \\
\hline \multirow[t]{3}{*}{$\mathrm{KP}+$} & 12 & 1 & 05:KUN & 1 & 08:K15 \\
\hline & 40 & 1 & 010:KUN & - & \\
\hline & 46 & 1 & 03:K6 & - & \\
\hline \multirow[t]{8}{*}{$\mathrm{KP}$ - } & 12 & 1 & $09: \mathrm{K} 56$ & & \\
\hline & 15 & 1 & 010:KUN & - & \\
\hline & 23 & - & & 1 & 02:K3 \\
\hline & 24 & 1 & 01:K25 & - & \\
\hline & 25 & 1 & $02: \mathrm{K} 30$ & - & \\
\hline & 37 & 1 & 010:K52 & 1 & $010: K 52$ \\
\hline & 43 & 1 & 08:K60 & - & \\
\hline & 46 & 1 & 010:K52 & - & \\
\hline
\end{tabular}

$\mathrm{KP}=$ Kanagawa phenomenon.

$\mathrm{APA}=$ água peptonada alcalina .

$\mathrm{NaCl}=$ cloreto de sódio.
É interessante assinalar que as cepas caracterizadas antigenicamente, apenas os sorotipos 03:K6, 08:K15, 09:K56 e 010:K52 apresentaram resultado positivo frente ao teste de Kanagawa. Destas, 03:K6 e 010:K52 são reconhecidas como importantes causadoras de gastrenterite em diversas regiões do mundo. Tal fato mostra a relevância quanto a sua detecção, dado o reconhecimento quanto ao elevado poder de virulência para o homem, após ingestão de alimentos marinhos crus ou insuficientemente cozidos. Deve ainda ser acrescido que tais resultados confirmam a necessidade do uso de métodos mais sensíveis baseados em técnicas moleculares que fornecem dados valiosos para a ampliação dos conhecimentos sobre a circulação desse patógeno em nosso meio ${ }^{15}$.

Outrossim, destaca-se a relevância quanto ao efeito da temperatura de pré-cozimento dos mexilhões a qual demonstrou efetividade na redução da carga microbiana do alimento in natura. Esta assertiva tem por base a verificação quanto um menor percentual de isolamento de Vibrio parahaemolyticus a partir das amostras pré-cozidas. Outro aspecto interessante foi à observação de que todas as cepas isoladas após o processamento tecnológico de pré-cocção apresentaram resultados negativos no teste de Kanagawa. Esses confirmam a importância do précozimento de mexilhões na redução da carga microbiana inicial presente no alimento. Tais resultados são reforçados por estudos prévios que apontam que este procedimento tende a minimizar os riscos da contaminação do produto. Após a pré-cocção é importante manter o produto armazenado a temperatura inferior a $-18^{\circ} \mathrm{C}^{713}$.

Os resultados obtidos na presente investigação reforçam a relevância acerca dos riscos do consumo de mexilhões sem cozimento efetivo $\left(100^{\circ} \mathrm{C} / 15 \mathrm{~min}\right)$ que podem resultar em diferentes nosologias, entre as quais, manifestações gastrintestinais provocadas particularmente por microrganismos do gênero Vibrio. A desinformação a respeito desses riscos para a saúde humana, em especial indivíduos portadores de doenças crônicodegenerativas aumenta a importância de ofertar a população alimentos seguros sob o ponto de vista da Saúde Pública ${ }^{2} 17$.

Para o consumo de mexilhões pré-cozidos, a população deve obedecer algumas regras básicas como a conservação do produto sob refrigeração $\left(4^{\circ} \mathrm{C}\right)$ em ambiente limpo e sanitizado, seguido da etapa de cozimento à temperatura de $100^{\circ} \mathrm{C}$ por aproximadamente 15 minutos a fim de inativar possíveis microrganismos remanescentes das etapas anteriores. É importante que o consumidor seja alertado quanto à importância do cumprimento das regras básicas de higiene durante todas as fases de manipulação e preparo do alimento que previnem a contaminação cruzada ou recontaminação do alimento pronto para consumo ${ }^{713}$.

A análise microbiológica dos mexilhões in natura e précozidos revelou a incidência de Vibrio parabaemolyticus neste tipo de alimento, o que constitui sérios riscos para o homem. Portanto, assinala-se à necessidade urgente de adoção de medidas corretivas e preventivas baseadas nas Boas Práticas de Manufatura, bem como a importância da maior participação institucional das Vigilâncias Sanitária e Epidemiológica no processo de aprimoramento tecnológico na cadeia de produção 
de alimentos. Essas medidas, se adotadas em conjunto, podem auxiliar na melhor qualidade dos mexilhões oferecidos ao mercado consumidor e na diminuição dos riscos de ocorrência de Doenças de Transmissão Alimentar veiculadas, particularmente por alimentos de origem marinha.

\section{REFERÊNCIAS}

1. Chowdhury A, Ishibashi M, Thiem VD, Tuyet DT, Tung TV, Chien BT, Siedlein LVL, Canh DG, Clemens J, Trach DD, Nishibuchi M. Emergence and serovars transition of Vibrio parabaemolyticus pandemic strains isolated during a diarrhea outbreak in Vietnam between 1997 and 1999. Microbiology of Immunology 48:319-327, 2004.

2. Elhadi N, Radu, S, Chen, CH, Nishibuchi, M. Prevalence of potentially pathogenic Vibrio species in the seafood marketed in Malaysia. Journal of Food Protection 67: 1469-1475, 2004.

3. Kaysner CA, DePaola Jr A. Vibrio cholerae, V. parahaemolyticus, V. vulnificus, and Other Vibrio spp., Bacteriological Analytical Manual, $8^{\text {th }}$ Edition, http://www.cfsan.fda.gov/ ebam/bam-9.html, 2004.

4. Gonzalez EN, Cachicar V, Acevedo C, Rioseco ML, Vergara JA, Cabello F, Romero J, Espejo RT. Vibrio parahaemolyticus diarrhea, Chile, 1998 and 2004. Emerging Infectious Disease 11:129-131, 2005.

5. Heitmann IG, Jofre LM, Hormazabal OJC. Review and guidelines for treatment of diarrhea caused by Vibrio parabaemolyticus. Revista. Chilena de Infectologia 22:131-140, 2005.

6. Hondo S, Goto I, Minematsu I, Ikeda N, Asano S, Ishibashi M, Kinoshita Y, Nishibuchi M, Honda T, Miwatani T.. Gastroenteritis due to Kanagawa negative Vibrio parahaemolyticus. Lancet 1:331-332, 1987.

7. International Comission on Microbiological Specifications for Foods. APPCC na qualidade e segurança microbiológica de alimentos. Comissão Internacional para Especificações Microbiológicas dos Alimentos. Varela, São Paulo, 1997.

8. Johnson, DE, Weinberg, L, Clarkoswki, J, West, PA, Colwell, RR. Wound infection caused by Kanagawa-negative Vibrio parabaemolyticus. Journal of Clinical Microbiology 20:811-812, 1984.
9. Lim TK, Stebbings AE. Fulminant necrotising fasciitis caused by Vibrio parahaemolyticus. Singapore Medicine Journal 40:596-597, 1999.

10. Magalhães V, Lima RA, Tateno S, Magalhães M. Human gastroenteritis associated with Vibrio parabaemolyticus in Recife, Brazil. Revista do Instituto de Medicina Tropical de São Paulo 33: 64-68, 1991.

11. Manual de Bergey. Manual of Determinative Bacteriology. $9^{\text {th }}$ edition, Baltimore: Williams \& Wilkins, p. 516-550, 1994.

12. Martinez-Urtaza J, Lozano-Leon A, DePaola A, Ishibashi M, Shimada K, Nishibuchi M, Liebana E. Characterization of pathogenic Vibrio parabaemolyticus isolates from clinical sources in Spain and comparison with Asian and North American pandemic isolates. Journal of Clinical Microbiology 42:4672-4678, 2004.

13. Muntada-Garriga JM, Rodriguez-Jerez JJ, Lopez-Sabater EI, Mora-Ventura MT. Effect of chill and freezing temperatures on survival of Vibrio parahaemolyticus inoculated in homogenates of oyster meat. Letters of Applied Microbiology 20:225-227, 1995 .

14. Nair GB, Hormazabal OJC. The Vibrio parabaemolyticus pandemic. Revista Chilena de Infectologia 22:125-130, 2005.

15. Nakaguchi Y, Okuda J, Iida T, Nishibuschi M. The urease gene cluster of Vibrio parabaemolyticus does not influence the expression of thermostable direct hemolysin (TDH) gene or the TDH related hemolysin gene. Microbiology of Immunology 47:233-239, 2003.

16. Pereira CS, Viana CM, Rodrigues DP. Vibrio parabaemolyticus produtores de urease isolados a partir de ostras (Crassostrea rhizophorae) coletadas in natura em restaurantes e mexilhões (Perna perna) de banco natural. Ciência e Tecnologia de Alimentos 24:591-595, 2004.

17. Revillo MJ, Ruiz MA, Uriel B, Garcia JCZ, Garcia JBM. Acute gastroenteritis caused by urease positive Vibrio parahaemolyticus in an immunocompromised patient. Enfermedades Infecciosas de Microbiologia Clinica 18:143-144, 2000.

18. Rippey SR. Infectious disease associated with molluscan shellfish consumption. Clinical Microbiology Reviews 7: 419-425, 1994. 